\title{
Outra política: Socialismo, democracia e emancipação
}

\author{
Another Politics: Socialism, Democracy, and Emancipation
}

\author{
Rúrion Melo \\ rurion@usp.br \\ (Universidade de São Paulo, São Paulo, Brasil)
}

\begin{abstract}
Resumo: 0 presente artigo aborda as análises de Fausto sobre a esquerda revolucionária e o socialismo democrático com o intuito de mostrar que sua proposta de refundação do socialismo ainda permaneceria vinculada à alternativa "reforma ou revolução" e daria pouco espaço tanto para a atuação dos movimentos sociais quanto para um conceito mais radical de democracia. Em seguida, apoiando-me nas considerações de Jürgen Habermas, desenvolvo a tese de acordo com a qual a orientação emancipatória vinculada ao socialismo teria de ser reatualizada de modo a poder incorporar uma pluralidade de sentidos da emancipação da dominação, os quais não se deixam mais apreender nos clássicos paradigmas da revolução e da reforma do capitalismo.
\end{abstract}

Palavras-chave: Ruy Fausto; Jürgen Habermas; socialismo; democracia; emancipação; lutas sociais.

\begin{abstract}
The article addresses Ruy Fausto's analysis of the revolutionary left and democratic socialism in order to show that his proposal for a refoundation of socialism would still remain linked to the alternative "reform or revolution" and would give little space to both the action of social movements and a more radical concept of democracy. Then, relying on Jürgen Habermas' considerations, I develop the thesis according to which the emancipatory orientation linked to socialism would have to be reactualized in order to incorporate a plurality of senses of emancipation from domination, which can no longer be apprehended in the classic paradigms of revolution and reform of capitalism.
\end{abstract}

Keywords: Ruy Fausto; Jürgen Habermas; socialismo; democracy; emancipation; social struggles.

Em resenha escrita por ocasião da publicação do livro $A$ esquerda difícil, de Rui Fausto (2007), eu havia apresentado brevemente o argumento de que, embora o autor contribuísse com uma reflexão fundamental acerca dos limites da esquerda revolucionária, sua proposta para dar continuidade à tradição crítica do socialismo democrático ainda permanecia presa, em certa medida, ao quadro dos paradigmas revolucionários ou reformistas. Isso ocorria, de acordo com meu argumento, porque Fausto também demonstrava muito ceticismo e desconfiança em relação às possibilidades democratizantes dos movimentos sociais, considerando-os no mais das vezes antidemocráticos e, no limite, tendencialmente totalitários (Melo, 2008). 
Eu gostaria de retomar as análises de Fausto sobre a esquerda revolucionária e o socialismo democrático, sublinhando tanto a ideia de que suas considerações ainda permaneceriam vinculadas à alternativa "reforma ou revolução" quanto o pouco espaço deixado em sua formulação para a atuação dos movimentos sociais e, por seu turno, para um conceito mais radical de democracia (I). Em seguida, apoiando-me nas considerações de Jürgen Habermas, desenvolvo a tese de acordo com a qual a orientação emancipatória vinculada ao socialismo teria de ser reatualizada de modo a poder incorporar uma pluralidade de sentidos da emancipação da dominação, os quais não se deixam mais apreender nos clássicos paradigmas da revolução e da reforma do capitalismo (II).

A publicação de Caminhos da esquerda: Elementos para uma reconstrução, em 2017, marca o fim de um ciclo de reflexões surpreendentes de Ruy Fausto sobre a relação entre socialismo, capitalismo e democracia. Certamente, há muito tempo Fausto se dedica a pensar a tradição filosófica de Marx e do marxismo, legando-nos livros de referência para a análise entre lógica e política. ${ }^{1}$ No entanto, o último ciclo de suas publicações coloca em primeiro plano um diagnóstico crítico fundamental sobre o paradigma revolucionário, sobre as consequências antidemocráticas das políticas comunistas, um balanço necessário sobre o futuro das esquerdas. ${ }^{2} \mathrm{E}$ Fausto não se limitou a tratar da experiência internacional do paradigma revolucionário e criticar enfaticamente o totalitarismo de esquerda; também a realidade intelectual e política do Brasil e, em particular, os desafios da esquerda brasileira se mantiveram no centro de suas preocupações.

Penso que o projeto de Fausto delineado nesses textos, projeto ao mesmo tempo imprescindível e ambicioso, poderia ser organizado em dois momentos. Mantendo-se sempre atento à relação dialética entre lógica e política, todo o esforço de reconstrução teórica e histórica parece orientado pela preocupação acerca da "história dos efeitos" da tradição socialista e suas tensões com o marxismo revolucionário. Ou seja, Fausto evidentemente não se restringe a apontar os “descaminhos totalitários” da esquerda revolucionária, preocupado, além disso, em

1 Refiro-me em especial aos dois primeiros tomos de Marx: lógica e política (1983, 1987). 0 terceiro tomo, publicado somente em 2002, embora dê continuidade às "investigações para uma reconstituição do sentido da dialética”, já incorpora de maneira explícita uma longa preocupação com a conjuntura política do período e com as orientações da esquerda em relação aos desafios que se impunham no início dos anos 2000.

2 Embora boa parte dessa preocupação com a atualidade política das esquerdas já tivesse sido incorporada à longa "introdução geral” do tomo III de Marx: lógica e política (2002), entendo que esse diagnóstico é apresentado apenas no último ciclo de publicações ao qual eu me referi, mais precisamente em Fausto (2007, 2009, 2017a e 2017b). 
"retomar a tradição do socialismo não-marxista no que ela teve de democrática, de não-comunista" (Fausto, 2007, p. 249). ${ }^{3}$ E esta retomada significa uma verdadeira "refundação do projeto socialista" (idem, p. 250), o empenho autêntico de um intelectual de esquerda que, ao dialogar com sua própria tradição, procura encontrar uma saída para os desafios do tempo presente. ${ }^{4}$

Contudo, em outra ocasião, identifiquei uma questão na reflexão de Fausto a respeito do destino da esquerda que, no contexto do presente artigo, eu gostaria de retomar e, em certa medida, desenvolver. Segundo o argumento central apresentado em minha resenha (Melo, 2018), Fausto avaliava as dificuldades do paradigma "revolucionário" sem, no entanto, estender em igual medida suas críticas ao paradigma "reformista". Isso teria ao menos duas consequências. Uma reflexão sobre o destino e a atualidade da esquerda implicaria rever igualmente tanto concepções revolucionárias quanto reformistas, as quais constituíram juntas a quase totalidade de suas orientações teóricas e práticas. Por esta razão, a alternativa para darmos continuidade à orientação emancipatória que marcou movimentos políticos e teorias de esquerda, como os entendo, teria de superar a dicotomia revolução ou reforma do capitalismo. Além disso, afirmei também que um projeto aberto e plural de "democracia radical", ligado às disputas e aspirações dos movimentos sociais, permitir-nos-ia desenvolver atualmente sentidos emancipatórios para além dos tradicionais paradigmas da esquerda (revolucionário e reformista). No entanto, e aqui consistia o centro do meu argumento na ocasião, isso exigiria incorporar à reflexão crítica e autocrítica a respeito da esquerda um conceito mais robusto e

3 Marx e o marxismo ocupam posições diferentes no escopo geral da argumentação. Fausto é extremamente rigoroso em sua análise dos textos de Marx, em especial quando se trata da concepção de democracia pressuposta em seus textos políticos. Mesmo assim, podemos afirmar que Fausto procura manter em seu projeto muito mais do próprio Marx do que da tradição do marxismo revolucionário. "Minha tese", afirma Fausto, "é a de que o marxismo como política e, em boa parte, como filosofia da história, envelheceu [...] mas ele continua sendo sólido, sem dúvida, em grandes linhas, como crítica do capitalismo. Quantos defendem essa perspectiva complexa? Muitos poucos. $\mathrm{E}$, entretanto, estou convencido de que só ela pode oferecer uma saída para a esquerda, em todo mundo" (Fausto, 2009, p. 3). Não posso discutir aqui as diferenças e as implicações da discussão que Fausto faz de Marx como crítico da economia ou da política. Ele retoma os mencionados potenciais não esgotados em Fausto (2017b, capítulo 5). Eu procuro discutir o conceito do político de Marx em Melo (2013). Para um balanço geral acerca do debate sobre os potenciais de Marx e do marxismo para a teoria crítica, cf. Habermas (2013).

4 Fausto foi muitas vezes questionado por ter se empenhado em um longo balanço crítico da esquerda, ressaltando os riscos totalitários da tradição à qual ele mesmo pertencia, embora não tivesse dedicado esforço similar em seus textos para criticar a direita. Fausto sempre foi muito direto em relação a este ponto: "É que eu falo para a esquerda" (Fausto, 2009, p. 244). Ele era plenamente consciente dos riscos que uma política de direita, conservadora e autoritária, representava para os defensores de um socialismo democrático. 0 crescimento da direita mundial, não somente no Brasil, tornou patente o fato de que "a tarefa de repensar o destino da esquerda ganhou ainda mais urgência" (Fausto, 2017b, p. 9), pois "diante dessa situação, a esquerda deve mais do que nunca buscar os caminhos da unidade. Isso vale tanto para o Brasil como para a Europa e os Estados Unidos. Mas a união das esquerdas não é incompatível com a discussão interna. Eu diria, inclusive, o contrário. A união só poderá vir com base numa discussão profunda dos problemas no interior da esquerda" (idem, p. 8). 
radical de democracia. É esta segunda consequência, em que se trata de vincular democracia e condições emancipatórias, que eu gostaria de discutir.

Quando se trata de "injetar mais democracia" (Fausto, 2007, p. 239) na tradição revolucionária, as alternativas parecem ser de dois tipos: pela via de um reformismo mais reflexivo ou a partir dos movimentos sociais. Ainda assim, nenhuma das duas opções estaria isenta de um processo de democratização. No que diz respeito à atuação dos movimentos sociais, seria preciso democratizá-los radicalmente com o intuito de evitar certos riscos "quase-totalitários"5. Esse temor de Fausto diante dos movimentos sociais em geral acabou, na verdade, reforçando uma saída de teor mais reformista (mesmo que não restrita à política partidária) para os desafios identificados na tradição revolucionária. Já no contexto de publicação de $A$ esquerda difícil, procurei chamar assim atenção para as consequências indesejáveis de um conceito de democracia radical aparentemente fechado, por assim dizer, às energias sociais produzidas de baixo para cima:

Ora, não parece possível uma reorientação emancipatória da esquerda sem que se enfrente com mais profundidade a questão da "democracia radical" - e isso significa, segundo nossa perspectiva, que o maior "desafio" não consiste na aposta reformista, mas sim em "radicalizar" ainda mais o "espírito radical democrático" aludido por Ruy Fausto. [...] 0 "espírito radical democrático" só pode ser reconstruído com instrumentos teóricos capazes de identificar as diferentes experiências de autodeterminação de sociedades modernas altamente complexas e pluralistas, as quais ampliam significativamente a agenda política da esquerda e apontam para uma orientação teórica e prática não mais limitada ao quadro reformista ou revolucionário (Melo, 2008, p. 148).

No meu entender, as publicações de Fausto depois de A esquerda difícil, também dedicadas a pensar a tradição revolucionária e, em especial, suas consequências antidemocráticas, não ofereceram novos esclarecimentos sobre o conceito de democracia radical pressuposto, mais especificamente em relação ao papel dos movimentos sociais. Na verdade, apenas em uma nota de rodapé, que foi adicionada ao final de uma entrevista republicada no seu livro de 2009, Fausto parece vincular sua concepção de democracia radical com a perspectiva dos movimentos sociais. Ao refletir rapidamente sobre o plano político que poderia orientar a "luta legal" (no sentido de ser uma luta conforme ao Estado democrático de direito) do socialismo mundial contra o capitalismo, Fausto afirma o seguinte:

No plano político, ela [a "luta legal"] deve ter um programa de democratização radical - e antitotalitária (essa precisão se impõe porque existe um pseudorradicalismo

5 Como afirma o autor, era preciso "injetar democracia nos movimentos sociais em geral essencialmente 'negativos' e sujeitos a tentações quase-totalitárias” (2007, p. 239). Mesmo em textos anteriores, o balanço dos movimentos sociais é bastante negativo. Ao falar da dinâmica política instaurada nas periferias do capitalismo, onde, em suas palavras, ocorreria uma "decomposição progressiva da vida civil", Fausto se restringe a dizer que existem ali "movimentos de 'resistência' muitas vezes inteiramente ‘degenerados' ou simplesmente regressivos” (Fausto, 2002, p. 71). 
totalitário) - de todas as instituições, das empresas ao parlamento. As formas de luta continuam sendo as mobilizações populares, a luta sindical e estudantil, e a luta parlamentar (Fausto, 2009, p. 248).

A ausência de uma presença mais decisiva dos movimentos sociais no projeto de um socialismo democrático, principalmente no contexto em que se trata de denunciar, por assim dizer, déficits democráticos e até excessos totalitários da esquerda, remonta a dificuldades presentes nas origens teórico-conceituais questionadas pelo autor. Por um lado, porque, de acordo com Fausto, sobretudo a tradição comunista havia evitado tanto uma reflexão sobre a democracia quanto acerca da violência daí também a ausência de uma discussão crítica sobre o totalitarismo (Fausto, 2009, 2017a). Não é por acaso que, no conjunto de textos em que se dedica à autocrítica da esquerda, totalitarismo, violência e ausência de democracia são como que fios condutores de toda sua reconstrução. E, na visão do próprio Fausto, é inegável o componente emancipatório inscrito na democracia, sem o qual o próprio projeto do socialismo seria inviável. Contudo, tendo em vista sua condução revolucionária, ideais emancipatórios e emprego da violência passaram a andar juntos, aproximando de maneira indesejada marxismo revolucionário e totalitarismo. ${ }^{6}$

No meu entender, essa teria sido uma das razões para que a refundação do socialismo proposta por Fausto se concentrasse no acerto de contas com as tendências totalitárias das correntes comunistas, sobretudo ligadas ao marxismo revolucionário, sem que uma revisão também ampla e radical da vertente reformista, comparável a suas críticas ao paradigma revolucionário, estivesse incluída nesse movimento de revisão da esquerda ${ }^{7}$. Por conseguinte, isso abre caminho para uma equiparação entre democracia e reforma. O projeto socialista de Fausto, como se sabe, deve ser democrático (portanto, avesso à violência), antipopulista e, claro, anticapitalista. Por um lado, essa violência não se internalizou no paradigma reformista, ou seja, tendências totalitárias foram represadas na perspectiva da reforma em virtude da relação com o a tradição do liberalismo político-jurídico. Por outro lado, isso se combina à concessão realista do autor para a implementação desse projeto, que passa necessariamente por algo que não cabia no esquema do materialismo histórico de Marx: ainda que capitalismo e democracia sejam contraditórios, precisamos, afirma Fausto, ser capazes de diagnosticar "algo como um círculo quadrado" (Fausto, 2009, p. 242), ou seja, a possibilidade de encontrar alternativas progressistas mesmo

6 Como sugere o autor, "a democracia não é visível [na tradição do marxismo revolucionário] porque ela só é pensável como exigência de libertação progressiva [...] porque democracia significa resistência a todas as violências, revolucionárias, contrarrevolucionárias ou outras. A democracia se pôs em evidência na luta contra a hybris da violência do Estado, a violência totalitária" (Fausto, 2009, p. 20).

7 Considero perfeitamente possível defender e criticar o reformismo, simultaneamente. E nisso Fausto está correto. Suas críticas se dirigem, sobretudo, ao "reformismo adesista" (2017b), permitindo-o assim defender um tipo de reformismo crítico e, nos seus próprios termos, democrático. 
no contexto conservador de um "capitalismo democrático" (que se distingue do não democrático pela mediação das leis e pela combinação com políticas de Estado). A saída reformista, que incorpora, por assim dizer, o propósito de um socialismo democrático ainda não plenamente realizado, pode ser igualmente democrática e, na perspectiva atual, permitir implementar um capitalismo combinado com controles estatais, redistribuição de renda e estímulo a uma economia solidária. Note-se que, além disso, o projeto de reconstrução da esquerda proposto por Fausto não pode voltar as costas aos riscos globais do capitalismo sobre o meio-ambiente, justificando a inclusão de uma robusta "agenda ecológica" (Fausto, 2017b, p. 91).

Mas há ainda um argumento adicional. Se revolução, violência e totalitarismo estão interconectados teórica e historicamente, o mesmo não ocorre com o próprio conceito de capitalismo. Ou seja, Fausto não acredita que o capitalismo se iguala necessariamente à violência, ou que a violência seja intrínseca ao capitalismo (mesmo que o capitalismo, para Fausto, produza historicamente formas violentas, como, por exemplo, a exploração dos trabalhadores, a devastação ambiental, as desigualdades sociais etc.). Logo, é preciso evitar o perigo, comum na esquerda, de

confundir crítica do capitalismo e crítica da democracia, sob o pretexto de que a democracia seria a forma política do capitalismo. Nada mais funesto. A ideia de que o capitalismo (e mais ainda o capitalismo democrático) seria o mal absoluto - isso resume todo o meu argumento - tem as piores consequências: o capitalismo é, sob muitos aspectos, um "mal”, mas, se ele for visto como a forma absoluta do mal, não veremos o mal absoluto, ou pelo menos tudo aquilo que é pior do que o capitalismo democrático [...] Hoje temos no mundo o triunfo [...] de um capitalismo que é ao mesmo tempo (imperfeitamente) democrático e imperialista (Fausto, 2002, p. 71).

No conjunto dessa autocrítica da esquerda, portanto, democracia e reforma são superiores à revolução porque se opõem em igual medida à violência totalitária e, no outro plano do argumento, são compatíveis com um capitalismo socialmente domesticado (ainda que imperfeito). Um socialismo democrático reformista (ou uma orientação reformista de tipo socialdemocrata) termina por ser eleito como a melhor alternativa em relação aos desvios totalitários do paradigma revolucionário. Ainda que concorde com a quase totalidade das análises de Fausto, não sigo sua conclusão (até porque, sobretudo vindo de alguém como Fausto, essa posição acaba reforçando de maneira indesejada a ideia conservadora comum de que o "reformismo" teria sido, em definitivo, o vencedor). E aqui eu gostaria de destacar apenas dois pontos. Em primeiro lugar, diante da alternativa "reforma ou revolução", não se trata mais de simplesmente apontar qual dos lados, afinal, teria saído vencedor, pois, no meu entender, o que caducou foi a própria alternativa em jogo (Melo, 2013, Primeira e Segunda Parte). Em segundo lugar, a forma com que democracia e reforma se assemelham no argumento de Fausto parece indicar a pressuposição de um conceito 
ainda bastante tradicional, pouco radical, por assim dizer, de democracia ${ }^{8}$. Mas é possível que, atualmente, uma autocrítica radical da esquerda, no limite a própria refundação do socialismo, prescinda também de uma democratização, igualmente crítica e radical, da democracia? No meu entender, ao partirmos das aspirações e lutas dos movimentos sociais, só poderemos resgatar o sentido emancipatório vinculado ao socialismo se superarmos tanto o paradigma revolucionário quanto reformista e, além disso, vincularmos o propósito socialista a uma radicalização da própria democracia (idem, Terceira Parte).

Não há a menor dúvida de que a compreensão das razões da bancarrota do socialismo real e as incertezas sobre o futuro da esquerda mobilizaram muitos intelectuais em todas as partes do mundo. ${ }^{9}$ Jürgen Habermas dedicou muitas análises e reflexões ao propósito de diagnosticar a necessidade de revisão da esquerda, a pensar sobre os riscos antidemocráticos do comunismo, a relação com Marx e a herança marxista, em especial o esgotamento dos paradigmas teóricos e práticos das orientações emancipatórias do socialismo e as possibilidades de reatualização de seus ideais transformadores nas lutas sociais em favor de uma radicalização da democracia. ${ }^{10}$ Penso que suas reflexões podem nos auxiliar no prosseguimento da questão acerca do que ainda significaria socialismo hoje, sem deixar de se preocupar com a emergência dos novos movimentos sociais, formas de engajamento político da sociedade civil e as diversas manifestações de resistência e revolta que adentram a esfera pública. Ele nos ajuda, assim, a complementar nossas considerações sobre a superação dos paradigmas da reforma e da revolução e, além disso, indicar saídas

8 Ainda dois pontos adicionais: (1) Fausto não é explícito no projeto de reconstrução da esquerda em apontar alternativas propriamente revolucionárias. De acordo com sua lógica argumentativa, a hipótese que sustentaria essas alternativas passa necessariamente pelo caminho da nãoviolência, critério imprescindível na visão do autor para que processos revolucionários venham a ser democráticos. Mas a ausência de uma análise sobre "revoluções democráticas", e, por sua vez, a junção estreita entre revolução e violência, leva Fausto a reconstruir as possibilidades viáveis do projeto socialista pelo caminho de um reformismo democrático. (2) Não há em Fausto uma teoria da democracia que permitisse tematizar mais profundamente processos de formação política da opinião e da vontade e modelos alternativos, mais radicais, de democracia. Isso talvez abrisse ao autor novas possibilidades de reconstrução do socialismo democrático que apontassem para além de reforma e revolução, conforme tenho defendido.

9 Na verdade, essa reflexão acompanhou a própria história do socialismo e do comunismo desde pelo menos o século XIX. Cf. Lichtheim (1965), Rosemberg (1999) e Eley (2002). Para um balanço sobre os acontecimentos no final dos anos 1980 no Centro e no Leste da Europa, cf. Blackburn (2005) e Sebestyen (2009).

10 Não posso retomar aqui todos os aspectos da abordagem habermasiana sobre as críticas ao comunismo revolucionário, ao socialismo burocrático e sobre a atualidade do socialismo. Cf. Habermas (2013a, 2015a, especialmente 2021a). Para análises sobre o tema nas obras de Habermas, cf. Tomberg (2003), Specter (2010) e Müller-Doohm (2014). Eu procuro aprofundar essas questões em Habermas e desenvolver possibilidades para uma teoria crítica da democracia em Melo (2013 e 2014). 
para tais paradigmas na direção de um conceito radical de democracia.

Segundo Habermas, ainda que pareça paradoxal, a bancarrota do socialismo real significou, ao mesmo tempo, uma reatualização dos interesses emancipatórios inscritos nos próprios ideais da esquerda socialista. Acontece que agora essa reatualização se inscreveu nas promessas de uma democracia radical, as quais ganharam força com os movimentos de libertação e de autodeterminação política. Por isso, de início, a revisão da esquerda implica avaliar criticamente o esgotamento das referências teóricas e práticas que se cristalizaram nos paradigmas clássicos e permaneceram tolhidos, por assim dizer, pela dicotomia "revolução ou reforma" do capitalismo. Em Marx, bem como no marxismo de modo geral, a emancipação estava ligada à utopia da sociedade do trabalho (Habermas, 2015a). No entanto, essa vinculação com o trabalho marcou o ideal emancipatório da esquerda em seu conjunto, determinando assim tanto o paradigma revolucionário quanto o reformista, considerados historicamente concorrentes. O que parece ter passado sem tematização nas análises de Fausto seria o fato de que a alternativa entre esses paradigmas concorrentes sempre nos fez olhar para suas diferenças e, assim, escolher um ou outro, como se fossem incompatíveis. As preocupações de Habermas nos ajudam a modificar nosso enfoque de leitura: reforma e revolução "esgotaram suas energias utópicas" porque, antes de suas diferenças, ambas as alternativas compartilham da perspectiva comum ligada ao "paradigma produtivista de emancipação" (Melo, 2013, Primeira Parte). Ou seja, reforma e revolução estavam intimamente atreladas ao modelo de uma sociedade pensada em sua totalidade como uma sociedade do trabalho.

A pergunta levantada por Habermas acerca da atualidade do socialismo problematiza o núcleo comum desse paradigma produtivista: seria possível e desejável reduzir as novas reivindicações dos movimentos sociais à lógica do trabalho? Os próprios movimentos sociais já não estariam há muito tempo apontando para a perspectiva redutora desses paradigmas e desse modelo de sociedade do trabalho, propondo antes novos sentidos para as lutas emancipatórias? Portanto, temos de entender por que os novos e sempre plurais sentidos da luta pela emancipação da dominação, que constitui, para Habermas, o núcleo do conceito mesmo de socialismo, não cabem mais dentro da alternativa revolução ou reforma. O que as novas lutas sociais nos mostraram - ambientalismo, pacifismo, antirracismo, feminismo, movimentos LBTQIA+, dentre muitas outras - é que elas não são mais compatíveis com esses paradigmas emancipatórios tradicionais da esquerda, que eles são demasiadamente engessados para os sentidos plurais, abertos e autodefinidos da emancipação.

E isso vale, sem dúvida, para o paradigma reformista, que represa igualmente as energias transformadoras e democratizantes da sociedade. O diagnóstico de Habermas sobre o esgotamento das energias utópicas do paradigma reformista 
está atrelado à sua compreensão de alguns aspectos do contexto pós-liberal e seus efeitos colaterais sobre as possibilidades prático-políticas (intervencionismo estatal na economia, Estado de bem-estar social e democracia de massas), produzindo, de maneira ambígua, uma ampliada reificação social (Habermas, 1981, Capítulo 8). Por essa razão, os limites da estratégia reformista serão avaliados em relação a uma contradição inerente a seu próprio programa de compensações sociais. Ainda que o objetivo do Estado social tenha sido amenizar os efeitos destrutivos do sistema capitalista e, ao mesmo tempo, criar condições sociais mais justas por meio de uma distribuição equitativa das oportunidades e dos recursos, a sua implementação centralizadora e burocrática gerou aumento de controle sobre as esferas da vida social:

Em suma, ao projeto do Estado de bem-estar social como tal é imanente a contradição entre o objetivo e o método. Seu objetivo é a fundação de formas de vida igualitariamente estruturadas, que ao mesmo tempo deveriam liberar espaços de ação para a autorrealização individual e para a espontaneidade. Mas, visivelmente, esse objetivo não pode ser alcançado pela via direta de uma execução jurídicoadministrativa de programas políticos. 0 medium poder é sobrecarregado com a produção de formas de vida (Habermas, 2015a, p. 224).

Habermas de modo algum quer com isso afirmar que temos de recuar diante das conquistas de programas reformistas de bem-estar, pois não foi o Estado social enquanto tal que teria se revelado insuficiente. A contradição específica entre fins emancipatórios e meios administrativos revelou, antes, não ser possível realizar formas de vida emancipadas por meios administrativos. ${ }^{11} \mathrm{Na}$ verdade, simplesmente não temos, por enquanto, muitas alternativas para domesticar socialmente o capitalismo, o que traz à tona dificuldades centrais para essa perspectiva emancipatória. "É justamente a ausência de alternativas", afirma o autor,

talvez até mesmo a irreversibilidade dessas estruturas do compromisso sempre batalhado que nos coloca hoje diante do dilema de que o capitalismo desenvolvido não pode viver sem o Estado de bem-estar social - tanto quanto não pode viver com mais uma ampliação dele. As reações mais ou menos perplexas a esse dilema mostram que se esgotou o potencial de estímulo político da utopia ligada à sociedade do trabalho (idem, p. 225).

Ora, se o Estado social é ainda mais desejável que uma desregulamentação econômica (nos moldes do neoliberalismo), vemo-nos obrigados a não voltar as costas para suas contradições, principalmente para o engessamento produzido sobre a práxis política dos cidadãos, a qual deveria se realizar democraticamente de baixo

11 Habermas afirma literalmente o seguinte: “A socialdemocracia foi surpreendida pela lógica sistêmica do poder estatal do qual ela acreditou poder se servir como um instrumento neutro para implementar a universalização dos direitos civis com a ajuda do Estado social. Não foi o Estado social que se revelou uma ilusão, mas a expectativa de conseguir alcançar formas de vida emancipadas com meios administrativos" (2021b, p. 281). 
para cima. A centralidade do emprego do poder político pelo Estado se revelou inadequada para alcançar o objetivo substancial de apoio e proteção a formas de vida emancipadas. É precisamente com base nesse diagnóstico que Habermas pode concluir não um esgotamento geral dos sentidos da emancipação na atualidade, mas sim daquele sentido orientado pelo paradigma produtivista: " $O$ desenvolvimento do Estado de bem-estar social entrou em um impasse. Junto com ele, esgotaram-se as energias da utopia própria da sociedade do trabalho" (idem, p. 232). E isso tem consequências decisivas para a aposta no enfoque reformista:

Assim, a socialdemocracia paga duas vezes o preço por seu êxito. Ela renuncia à democracia radical e aprende a conviver com as consequências normativamente indesejadas do crescimento capitalista - também com os riscos especificamente sistêmicos do mercado de trabalho, que são "suavizados" pelas políticas sociais, mas não eliminados (Habermas, 2021b, p. 282)

Se, como dissemos antes, o fim do socialismo realmente existente não representou, para Habermas, o fim das lutas sociais em nossas sociedades, o mesmo vale para o impasse em que se encontra a alternativa reformista: com o esgotamento de seu modelo, não se esvaem as aspirações emancipatórias produzidas na base da sociedade. Pois as lutas sociais são as responsáveis por dar continuidade e atualizar os ideais emancipatórios do socialismo. Contrariamente, se restringirmos o potencial radicalmente democrático aberto pelos movimentos sociais às possibilidades da alternativa reformista, limitando, sobretudo, a democracia à instância burocráticoadministrativa do sistema político, não seria o Estado a ser socialmente domesticado, mas tão somente a própria democracia, engessando a práxis política autônoma dos cidadãos.

Diferentemente de um "enfoque de leitura concretista" (Habermas, 2021b, p. 285), os conceitos que Habermas mobiliza de emancipação das formas de vida, de democracia radical e de socialismo, os quais iluminam aspectos uns dos outros, não são determinados de antemão por critérios substantivos; não delimitam, de maneira concreta, temas, objetivos, processos e portadores da emancipação (atores, grupos, classes, coletivos etc.); não partem de, nem produzem, imagens concretas do que deve ser a sociedade emancipada. E é justamente por isso que se pode reconhecer nas lutas existentes por mais autonomia, que são motivadas e articuladas em diversas experiências de dominação e injustiça, fagulhas do almejado ideal emancipatório (presentificado na multiplicidade de seus sentidos). Pois, na concepção de teoria crítica elaborada por Habermas, o socialismo se deixa compreender tão somente como a tentativa de deter a destruição das formas de vida, ou, como afirmou de modo peculiar, "o socialismo significa, sobretudo, saber o que não se quer, aquilo de que se quer emancipar” (Habermas, 2015b, p. 120). Socialismo, para Habermas, diz respeito a toda aspiração e luta em prol da emancipação da dominação. Em 
sociedades como a nossa, perpassadas por crises, injustiças, poder e dominação, trata-se de um ideal necessário e irrenunciável ${ }^{12}$, do qual não podemos abrir mão. A formulação oferecida pelo autor pode ser compreendida de maneira abstrata (em oposição à imagem de como concretamente deve ser uma sociedade emancipada) do seguinte modo:

O socialismo significa uma tentativa, tanto sujeita a falhas quanto viável, além de apoiada em autocorreções, de diminuir ao menos, com o esforço coletivo, a dor identificável, a injustiça identificável, as repressões evitáveis [...] Essa perspectiva deixa-se caracterizar abstratamente com facilidade: a saber, deter a destruição de formas de vida solidárias e criar novas formas de convívio solidário, portanto, formas de vida com possibilidades de expressão enfática, com espaço de ação para as orientação prático-morais, ou seja, para formas de vida que oferecem um contexto no qual a própria identidade e a dos outros podem se desenvolver de maneira não problemática, não danificada (idem, ibidem).

Além de evitar uma definição demasiado concreta do que seja socialismo (a qual, como dito, acaba por engessar os sentidos plurais da emancipação da dominação que têm sido incorporados às novas lutas sociais e precisam ser decididos pelos próprios concernidos), Habermas procura articulá-la de maneira imanente à sua própria concepção normativa de democracia radical (aquela que precisa ser resgatada do cerne do projeto do Estado democrático de direito). No livro Facticidade e validade, Habermas explicita essa interconexão estreita de socialismo e democracia radical em termos normativos:

Após o colapso do socialismo de Estado e com o fim da "guerra civil mundial", tornouse manifesto o erro teórico do partido derrotado: ele confundiu o projeto socialista com o projeto - e a imposição forçada - de uma forma de vida concreta. Contudo, se concebermos "socialismo" como súmula das condições necessárias para formas de vida emancipadas, sobre as quais os próprios participantes precisam primeiro se entender, reconhece-se que a auto-organização democrática de uma comunidade de direito também forma o núcleo normativo desse projeto (Habermas, 2020b, p. 28).

Vê-se assim como tais conceitos permitem compreender mais especificamente que a emancipação da dominação das formas de vida constitui o cerne normativo a ser priorizado na resposta à pergunta “o que significa socialismo hoje?” - a qual só pode ser respondida concretamente com as lutas dos movimentos sociais e suas pretensões democrático-radicais. Portanto, somente uma sociedade radicalmente democrática - em que as formas de vida plurais podem se expressar de maneira enfática e os participantes podem definir autonomamente os termos de sua auto-organização - é capaz de realizar, ainda que sujeita a falhas, o propósito emancipatório atribuído ao socialismo.

12 Compare-se, nesse mesmo sentido, as formulações de Habermas sobre o ideal emancipatório "irrenunciável" no presente, que estava inscrito já nas revoluções burguesas em Habermas (2020a, p. 632). 
Se socialismo significa "aquilo de que se quer emancipar", podemos identificar a mesma preocupação com a superação prática das formas existentes de dominação na multiplicidade das vozes dos movimentos sociais. Uma sociedade democrática, que é incapaz de superar o racismo, o sexismo, a opressão, a xenofobia, a homofobia, a desigualdade brutal, é uma sociedade ainda muito distante dos ideais emancipatórios do socialismo. E a realização desses ideais passa pelo combate a tais questões (já que, superar o racismo, o sexismo ou a homofobia é precisamente querer se emancipar de ameaças e violências contra as formas de vida democráticas). Portanto, é preciso contar com um conceito atualizável de socialismo que seja compatível com essa diversidade dos sentidos da emancipação (sempre atrelados à diversidade de experiências negativas que as motivam). Caso contrário, esse projeto de socialismo não seria suficientemente democrático, chegando mesmo a ser incompatível com a democracia enquanto tal. Isso é importante no contexto de nossa discussão porque a partir dos movimentos sociais conseguimos diagnosticar experiências diferentes das injustiças e opressões (desigualdades, violações de direitos humanos, da xenofobia, intolerância e perda de solidariedade, do racismo, do sexismo, da homofobia etc.), bem como acompanhar visões e demandas transformadoras que abrem ao futuro possibilidades práticas para a ação política. Eles permitem desenvolver um potencial para superar paradigmas emancipatórios engessados, 0 qual seja capaz de reconfigurar nossa vida e nossa sociedade, sempre aspirando a uma outra política, isto é, alternativas aos sofrimentos, humilhações, opressões e injustiças estruturais, buscando incessantemente formas de vida mais democráticas (Dixon, 2014). Em outros termos, não haverá refundação possível do socialismo sem o ímpeto radicalmente transformador dos movimentos sociais do presente. Pois são eles os únicos responsáveis por reverter as relações de poder, renovar as gramáticas democratizantes que, mesmo de maneira parcial, já se encontram na base da nossa cultura política, e também influenciar mudanças no sistema político, ou seja, lutar pela democratização nas instituições formais do Estado de direito (Habermas, 2020b, capítulo 8).

Cabe destacar ainda uma questão importante no contexto de nossa discussão. Habermas também está atento àquilo que preocupava Fausto na relação entre revolução e violência, que acompanhou não somente as revoluções comunistas, mas também esteve presente desde a Revolução Francesa e as críticas ao "terror”. Segundo Fausto, a soberania popular, mais precisamente, a liberação de energia popular transformadora de baixo para cima, não constitui, por si mesma, garantia de não-violência. É principalmente em suas análises sobre a Revolução Russa que Fausto tematiza de maneira exemplar a torção que o poder constituinte pode produzir contra si mesmo (Fausto, 2017a). Na mira de suas análises estão não apenas a usurpação da energia emancipatória pelo aparelho burocrático e centralizador do Estado, mas 
também a violência social por excelência, que pode habitar uma agitada soberania popular posta em movimento. Em outros termos, sem as devidas mediações, não se pode dizer que a liberação de uma energia social "de baixo para cima" já se qualifica de antemão como emancipatória, pois não há garantias de não-violência. Com as devidas proporções, este mesmo raciocínio concernente às consequências indesejadas dos movimentos revolucionários parece ser empregado em suas críticas aos novos movimentos sociais: padeceriam, em geral, do mesmo risco.

Em um mundo repleto de injustiça e de "não razão", os movimentos sociais representam para Habermas as únicas "partículas e fragmentos de uma 'razão existente' já incorporados nas práticas políticas, por mais distorcidas que possam ser" (Habermas, 2020a, p. 369), o "único buraco de agulha pelo qual tudo tem de passar" (Habermas, 2021b, p. 296). Seu pressuposto é o de que essa partícula de razão “já existe na história - nas conquistas dos movimentos sociais” (Habermas, 2021c, p. 138), nos ideais de autonomia privada e pública, de direitos humanos e de soberania popular. Contudo, de modo algum Habermas descarta o perigo da violência que pode acompanhar formas radicais de atuação desses movimentos (e que fizeram parte, como ele reconhece muitas vezes, da história das revoluções burguesas e socialistas). Na verdade, no plano da sociedade civil, seu diagnóstico indica antes de tudo uma tendência de repressão da diversidade, de confusão entre convicções republicanas e retrocesso nacionalista, de crescimento de vagas conservadoras da direita, do esgarçamento social, que coloca em conflito cotidiano cidadãos com visões de mundo divergentes, do surgimento de “contrapúblicos" que acabam desdobrando não apenas pautas e temas subalternos considerados emancipatórios, mas também acirram de maneira quase intratável os conflitos sociais. Sendo assim, os movimentos sociais podem ser igualmente ambíguos e complexos, exigindo um diagnóstico acurado de seus sentidos emancipatórios ou não emancipatórios. Ainda assim, Habermas é um defensor inconteste de atos de “desobediência civil”, e procura criticar com veemência a perseguição e a criminalização dos movimentos sociais. Isso para reforçar que, na esfera pública, ainda que sempre mediado por determinações jurídicas, mesmo no Estado de direito há um espaço politicamente indeterminado onde se estabelecem delicadas relações entre democracia e violência. ${ }^{13}$

Portanto, os movimentos sociais mostram para a esquerda que, mesmo depois

13 Essa discussão se concentra, em grande medida, no conceito de "desobediência civil" e na sua conexão com a violência. Cf. Habermas (2015c, 2020b, 2021d). Pois, uma vez que Habermas se refere em geral à desobediência civil como "atos não violentos de transgressão simbólica", muito se discutiu sobre os limites de sua concepção, em que a avaliação e a justificação dessas formas de ação direta da sociedade dependem diretamente desse caráter não violento. Ou seja, formas violentas de desobediência civil não poderiam ser consideradas emancipatórias no quadro de sua teoria. Para uma crítica dessa concepção habermasiana e uma defesa da incorporação refletida da violência na justificação do conceito de desobediência civil, cf. Celikates (2016, 2019). Para uma tentativa de balanço desse debate, cf. Melo (2019). 
da derrocada do comunismo, outra política é possível para além do capitalismo democrático; que o terreno reformista dependente de um sistema político altamente centralizador e profundamente burocrático não é capaz de, sem produzir efeitos colaterais indesejáveis, converter as experiências cotidianas dos sujeitos em novas possibilidades de autodeterminação e de autorrealização; que a dimensão das democracias representativas de massa não é suficiente para produzir decisões vinculantes consideradas legítimas aos olhos dos próprios cidadãos concernidos; em suma, que os meios jurídico-políticos organizados estatalmente não são o bastante para impedir a destruição das formas de vida e dar vazão às capacidades coletivas sem que a própria ideia do Estado de direito esteja apoiada sobre uma concepção robusta de democracia radical (Habermas, 2020b p. 29). As estruturas regulatórias do sistema político, que implementam um controle de cima para baixo, normalizam um modo de vida com pouco teor democrático. Mas uma vida "não danificada" depende da capacidade que temos de "mobilizar a arena inferior" (Habermas, 2015a) da sociedade em contraposição aos poderes das arenas superiores. Daí o risco de que uma concepção meramente reformista não baste para dar respostas aos déficits democráticos do Estado, aos riscos paternalistas dos controles centralizados, que passam ao largo da práxis política autônoma dos cidadãos. Em face dos desafios urgentes da nossa sociedade (desigualdades, violações, explorações, genocídios etc.), ainda podemos (e devemos) nos orientar pelos ideais do socialismo, pois ainda queremos superar as ameaças sistemáticas às nossas formas de vida. De modo algum se trata, no nosso contexto, de considerá-lo um estado já realizado. Por outro lado, ele não é absolutamente uma mera ideia sem efetivação. Emancipação é aspiração concreta e real à mudança e à transformação, que já se encontra inscrita nas lutas sociais. Esse é o sentido irrenunciável do socialismo e que hoje ainda subjaz aos potenciais emancipatórios enraizados nos processos de democratização impulsionados a partir da base da sociedade.

\section{Referências}

Blackburn, R. (org.) (2005). Depois da queda: O fracasso do comunismo e o futuro do socialismo. Rio de Janeiro: Paz e Terra.

Celikates, R. (2016). Rethinking Civil Disobedience as a Practice of Contestation: Beyond the Liberal Paradigm. Constellations, 23(1), 37-45. DOI: http://doi. org/10.1111/1467-8675.12216.

Celikates, R. (2019). Civilidade radical? Desobediência civil e ideologia de nãoviolência. Dissonância: Revista de Teoria Crítica. 3 (1), 23-69.

Eley, G. (2002). Forging Democracy: The History of the Left in Europe, 1850-2000. Oxford: Oxford University Press.

Fausto, R. (1983). Marx: Lógica e política. Tomo I. São Paulo: Brasiliense. 
Fausto, R. (1987). Marx: Lógica e política. Tomo II. São Paulo: Brasiliense.

Fausto, R. (2002). Marx: Lógica e política. Tomo III. São Paulo: Ed. 34.

Fausto, R. (2007). A esquerda difícil: Em torno do paradigma e do destino das revoluções do século XX e alguns outros temas. São Paulo: Perspectiva.

Fausto, R. (2009). Outro dia: Intervenções, entrevistas, outros tempos. São Paulo: Perspectiva.

Fausto, R. (2017a). O ciclo do totalitarismo. São Paulo: Perspectiva.

Fausto, R. (2017b). Caminhos da esquerda: Elementos para uma reconstrução. São Paulo: Companhia das Letras.

Habermas, J. (1981). Theorie des kommunikativen Handelns. Band 2. Frankfurt am Main: Suhrkamp.

Habermas, J. (2013a). “Direito natural e revolução”. In: Habermas, J. Teoria e práxis. São Paulo: UNESP.

Habermas, J. (2013b). "Entre filosofia e ciência: marxismo como crítica". In: Habermas, J. Teoria e práxis. São Paulo: UNESP.

Habermas, J (2015a). "A crise do Estado de bem-estar social e o esgotamento das energias utópicas”. In: Habermas, J. A nova obscuridade. São Paulo: UNESP.

Habermas, J. (2015b). "Política conservadora, trabalho, socialismo e utopia hoje". In: Habermas, J. A nova obscuridade. São Paulo: UNESP.

Habermas, J. (2015c). "Desobediência civil - a pedra de toque do Estado democrático de direito”. In: Habermas, J. A nova obscuridade. São Paulo: UNESP.

Habermas, J. (2020a). "Soberania popular como procedimento". In: Habermas, J. Facticidade e validade: Contribuições para uma teoria discursiva do direito e da democracia. São Paulo: UNESP.

Habermas, J. (2020b). Facticidade e validade: Contribuições para uma teoria discursiva do direito e da democracia. São Paulo: UNESP.

Habermas, J. (2021a). A revolução recuperadora. São Paulo: UNESP.

Habermas, J. (2021b). "Revolução recuperadora e necessidade de revisão da esquerda: o que significa socialismo hoje?”. In: Habermas, J. A revolução recuperadora. São Paulo: UNESP.

Habermas, J. (2021c). “Entrevista com Hans-Peter Krüger”. In: Habermas, J. A revolução recuperadora. São Paulo: UNESP.

Habermas, J. (2021d). “Monopólio do poder, consciência jurídica e processo democrático: primeiras impressões da leitura do parecer final da Comissão de Violência”. In: Habermas, J. A revolução recuperadora. São Paulo: UNESP.

Lichtheim, G. (1965). The Origins of Socialism. New York: Praeger.

Melo, R. (2008). Resenha sobre A esquerda difícil: Em torno do paradigma e do destino das revoluções do século XX e alguns outros temas, de Ruy Fausto. Cadernos de filosofia alemã, 11, 141-152. DOI: DOI: https://doi.org/10.11606/ issn.2318-9800.v0i11p141-152.

Melo, R. (2013). Marx e Habermas: Teoria crítica e os sentidos da emancipação. São 
Paulo: Saraiva.

Melo, R. (2014). Habermas et la nécessaire révision de la gauche. Rue Descartes, 76, 42-55. https://doi.org/10.3917/rdes.076.0042.

Melo, R. (2019). Legitimidade política e esfera pública: Disputando os sentidos da desobediência civil. Dissonância: Revista de Teoria Crítica, 3(1), 291-320.

Müller-Doohm, S. (2014). Jürgen Habermas: Eine Biographie. Frankfurt am Main: Suhrkamp.

Rosemberg, A. (1999). Democracia e socialismo. São Paulo: Global.

Sebestyen, V. (2009). A revolução de 1989: A queda do império soviético. Rio de Janeiro: Globo Livros.

Specter, M. (2010). Habermas: An Intellectual Biography. New York: Cambridge University Press.

Tomberg, F. (2003). Habermas und der Marxismus. Würzburg: Könighausen \& Neumann. 